\title{
Habitar o insabido: encontro, travessia, invenção
}

\author{
Habiter l'inconnu: rencontre, croisement, invention
}

\author{
Greciely Cristina da Costa ${ }^{1}$ \\ Universidade do Vale do Sapucaí
}

- RESUMO: Esse texto é resultado de um percurso constituído de estudo, afeto teórico e afeto-afeto, pois se trata de uma homenagem à professora e pesquisadora Eni Puccinelli Orlandi, cuja pesquisa é referência para as Ciências da Linguagem. Para traçar esse percurso, retomei seus escritos, em especial, prefácios de algumas de suas obras, em busca textualizar o encontro, a travessia e a invenção que fazem parte daquilo que inscreve a autora num laço indelével com as letras, com as palavras, com o silêncio, com a escrita, com a vontade de saber.

- PALAVRAS-CHAVE: Homenagem. Eni Orlandi. Análise de Discurso.

- RÉSUMÉ: Ce texte est le résultat d'un parcours d'étude, d'affection théorique et d'affection-affection, car il s'agit d'un hommage à professeure et chercheuse Eni Puccinelli Orlandi, dont la recherche est une référence pour les sciences du langage. Pour retracer ce parcours, j'ai repris ses écrits, surtout préfaces de certaines de ses œuvres, à la recherche de textualiser la rencontre, le croisement et l'invention qui font partie de ce qui inscrit l'auteure dans un lien indélébile avec des lettres, avec des mots, le silence, l'écriture, la volonté de savoir.

- MOTS-CLÉS: Hommage. Eni Orlandi. Analyse de discours.

Poesia

Gastei uma hora pensando em um verso que a pena não quer escrever. No entanto ele está cá dentro inquieto, vivo.

Ele está cá dentro e não quer sair.

Mas a poesia deste momento inunda minha vida inteira.

Carlos Drummond de Andrade

O real da homenagem, às vezes, não cabe naquilo que se escreve. Todavia, pode se inscrever numa letra lida, numa escrita imaginada/desejada, na falta de uma palavra, num traço de poesia. Ou seja, numa outra dimensão da escrita.

Em seu percurso histórico, a palavra homenagem é uma daquelas que estabelecem estreita relação de sentidos com outras palavras muito significativas em torno daquilo que diz respeito à honra, à admiração, à gratidão, em sua dimensão pública e política. A prática de homenagem é histórica e se dá, sobretudo, em razão do reconhecimento daquele que é homenageado.

Esse texto, que ora resulta de um percurso constituído de estudo, afeto teórico e afeto-afeto, é uma homenagem. Um gesto de reconhecimento e agradecimento a Eni

\footnotetext{
${ }^{1}$ Doutora em Linguística pela UNICAMP.greciely@gmail.com
} 
Orlandi, que se textualiza a partir de um percurso que fiz por seus escritos, em especial, pela leitura e retomada de prefácios de algumas das obras da autora cuja pesquisa é referência para as Ciências da Linguagem.

Dentre muitas coisas que aprendi com Eni Orlandi, é que não se pode dizer tudo. Há sempre ainda o que se dizer e há dizeres que precisam da falta para significar. Assim, de antemão, já alerto que, justamente, não almejo, nem seria possível dizer tudo, mas, viso dar relevo a partes da escritura da pesquisadora, professora, orientadora, que transformou a maneira pela qual a linguagem é compreendida e assim permitiu transformar o modo como se pode compreender o mundo pela linguagem.

Eni de Lourdes Puccinelli Orlandi, de família de imigrantes italianos, é filha de Angelina e Sebastião, é de Água Vermelha, vila praticamente fundada por seu avó Francesco Puccinelli, que se tornou distrito de São Carlos, interior de São Paulo. Morou em fazenda, estudou em escola rural. Foi alfabetizada antes da idade regular, pois ia, antes do ingresso formal, à escola com a irmã mais velha. Diferente das duas irmãs e do irmão, não foi para o colégio interno, estudou em escola pública.

Eni Orlandi, em uma entrevista que concedeu à revista Fragmentum, a qual farei aqui várias menções, relata que teve uma formação primária, ginasial e colegial muito boa, pois essa deu a ela a base de uma vida intelectual. Tendo tido professores ousados, ela também nunca teve medo de ousar.

Conta que seu pai sabia francês, grego, latim, letras clássicas. Ele ensinou a ela, por meio de uma brincadeira, como cortar a palavra, dividi-la, para chegar ao seu significado. Isso foi para ela uma grande revelação, porque ela percebeu como é que se podia saber o que as palavras dizem. Gosto e curiosidade a fizeram ir, além disso, na busca pela compreensão da linguagem.

Das fábulas familiares, guarda que sua mãe a pegava sozinha, deitada no chão, olhando as nuvens e contando histórias para si mesma.

Da avó Mariana, que só falava vêneto ou algumas palavras de um português italianado, em seu mais recente livro Eu, Tu, Ele discurso e real da história, Orlandi reflete sobre o fato de que ela e a avó conversavam cada uma em sua língua. Não era pela língua que se compreendiam. Mas, havia algo que nessa língua se dizia.

Eni Orlandi deixa ver que seu gosto e curiosidade pela linguagem constituem um traço fundamental na sua vida à medida que a descoberta da palavra e o gesto de formular a emocionam sempre:

\footnotetext{
Eu fico emocionada ainda, desde pequena eu tinha essa emoção de saber o que significavam as palavras e o que é a linguagem. Eu continuo a ter como se fosse infantil isso em mim até hoje, um sentimento infantil de descoberta quando eu encontro uma palavra ou uma formulação boa (SCHERER, 2004, p. 14).
}

Sobre seu percurso de formação, Orlandi relata que se preparou para o vestibular de Direito por influência de seu pai que tinha admiração pelo direito. Para isso, estudou muito, em especial com o estudo de latim, percebeu "a língua mesmo, como um jogo, como formas que se relacionavam" (SCHERER, 2004, p. 12). Ficou doente, teve hepatite, não fez o vestibular. Entrou em Letras, na Faculdade de Filosofia, Ciências e Letras de Araraquara.

Teve aulas de Literatura com Jorge de Sena, Crítica Literária com Casais Monteiro, Filosofia com Fausto Castilho, Economia com Paulo Singer, Psicologia com Dante Moreira Leite, Filologia Portuguesa com Clemente Segundo Pinho. Esse último foi quem disse a ela que o que ela fazia, e o que ela gostava de fazer, era Linguística e não Filologia. 
Em um momento em que a linguística ainda não existia, não fazia parte do currículo de Letras, Eni Orlandi começou seu percurso lendo, por conta própria, Saussure, Martinet e Benveniste. Foi procurar a linguística. Só quando ela estava no $3^{\circ}$ ano, a disciplina Linguística foi introduzida no curso para o $2^{\circ}$ ano, a partir de uma reivindicação dela e de seus colegas.

Assim que se formou foi para São Paulo, por causa da ditadura de 64. Foi para a USP fazer linguística, que não existia, mas que ela queria fazer.

Muitos não sabem, mas a Eni Orlandi, já na USP, batalhou com Lélia Ergolato e Emilio Justi para que houvesse Linguística Geral naquela universidade, para que a Linguística fosse autônoma em relação à Filologia. Depois, lutou para que a Análise de Discurso tivesse um lugar autônomo em relação à Linguística.

Em seu mestrado, trabalhou com o estruturalismo, com Hjmeslev. Reconhecida pelo professor Maurer, foi indicada por ele para assumir seu lugar na universidade quando ele se aposentou. Como professora, batalhou ainda mais intensamente pela Linguística com Izidoro Blinktein e Cidmar Paes.

Em 68 foi para Montpellier, na França, como leitora. Na sequência foi para Paris, fez doutorado em Vincennes, com o professor Prieto, que fazia uma linguística que trabalhava a questão da significação. Mas, como ela mesma relata, não era ainda 0 que ela procurava. Conheceu Foucault, Lacan, Greimas, Barthes, assistiu a aulas de Ducrot, estudava linguística ${ }^{2}$. No entanto, procurava mesmo algo relacionado ao sentido.

Em uma livraria do Quartier Latin, onde a vida intelectual era muito intensa, Eni Orlandi encontrou dois livros pareados: um de semântica de Julia Kristeva e o outro de Michel Pêcheux, Análise Automática do Discurso, recém-publicado. Ficou com o de Pêcheux. Segundo ela, o livro a impressionou porque falava da linguagem na relação com a política.

Retornou ao Brasil e, ainda, na USP, foi professora de Sociolinguística, Sociologia da Linguagem, Etnolinguística. Nas aulas dessas disciplinas começou a interrogar os pressupostos e a metodologia sobre os quais essas teorias se pautavam. Não aceitava a correlação traçada entre o linguístico e o social. Defendia a relação constitutiva entre um e outro. Vai escrever um pouco depois que o "discurso não separa linguagem e sociedade na história" (ORLANDI, 1994, p.54). No mestrado ministrou uma disciplina chamada Análise Sociolinguística do Discurso Pedagógico. Não era ainda Análise de Discurso. Todavia, foi por meio dessa disciplina que instalou o Discurso na USP.

Em 1979, já conhecida pelo seu trabalho, foi convidada para trabalhar Análise de Discurso na Unicamp. Mas, alguns professores não queriam que a Análise de Discurso fosse instalada no IEL. Eni Orlandi não recuou, deu continuidade aos seus estudos e pesquisas, ofereceu cursos, trabalhou com a Análise de Discurso na graduação e na pós-graduação. Ela conta que o interesse dos alunos pela Análise de Discurso foi decisivo para sua institucionalização. Em suas palavras:

Foi preciso que alunos se interessassem para que se configurasse um lugar de existência para essa disciplina, para o que eu tinha para falar disso e para quem. E aí, começou a ser muito forte [...] Eram pessoas que se perguntavam

\footnotetext{
${ }^{1}$ No exterior, além do pós-doutorado, de 1987 a 1988, na Universidade de Paris VII, Eni Orlandi foi professora visitante convidada na Universidade de Lausane, na Suíça, em 2008 e 1994; na École des Hautes Études en Sciences Sociales, na França, em 2004; na Univesidade de Paris III, em 2001; na Paris XIII, em 1997; na Universidade de Buenos Aires, na Argentina, em 1996; e na Universidade de Lancaster, na Inglaterra, em 1994; em 2015, da Universidade de Turim, na Itália. Em 2012, participou do Forum International de la Francophonie et du Multilinguisme, OIF/AUF Québec - Canadá.
} 
por esses pressupostos, eram pessoas que não se contentavam em aplicar simplesmente um conhecimento, no sentido mais banal, mas que se perguntavam por esse conhecimento que estavam praticando (SCHERER, 2004, p. 21-22).

$\mathrm{Na}$ Unicamp, deu início à institucionalização da Análise de Discurso com a formação de mestres e doutores. Ao todo, orientou 47 dissertações de mestrado, 42 teses de doutorado.

Deu continuidade aos seus estudos, traduziu vários textos de Pêcheux e dos pesquisadores de seu grupo, deu corpo e direção à pesquisa na Análise de Discurso com a realização de projetos que se tornaram disciplinas, linhas e programas de pesquisa. $\mathrm{O}$ primeiro projeto: A construção da brasilidade. Os dois mais atuais em andamento: Nas fronteiras da Linguagem, a indistinção: Práticas significativas, imaginário e vida social (da violência e da resistência), e Saindo do lugar e deslocando sentidos: a relação imigração/colonização nos volteios da narratividade.

Produziu as obras que são referências para as Ciências da Linguagem. Mais de 40 livros publicados, cerca de 73 capítulos de livro e 1 centena de artigos publicados em periódicos.

Com seu trabalho, com sua reflexão, persistência e compreensão deu um lugar disciplinar, de formação, de produção de ciência, à Análise de Discurso no Brasil.

Não parou por aí. Aliás, o percurso que estou traçando a respeito do percurso de Orlandi é feitura de cortes e recortes.

Por meio de convênios e/ou parcerias com pesquisadores franceses, tais como Sylvain Auroux e Francine Mazière, iniciou, na década de 80, o estudo das relações entre a produção de conhecimento sobre as línguas e a formação social e política do Brasil, dando especificidade à História das Ideias Linguísticas em/do nosso país. Assim, inaugurou mais um campo novo de questões.

A partir de 1992, coordenou o projeto temático Os Sentidos do Público no Espaço Urbano, que resultou na criação do Laboratório de Estudos Urbanos da Unicamp, um espaço multidisciplinar de pesquisa, no qual se pressupõe a relação entre linguagem, sujeito e história para a análise dos processos de significação, desencadeando pesquisas sobre a vida da cidade. Assim, esteve à frente da construção de uma nova área de conhecimento chamada Saber Urbano e Linguagem.

Em 1993, ganhou o Prêmio Jabuti em Ciências Humanas com o livro As formas do silêncio: no movimento dos sentidos. Esse livro foi traduzido para o francês e para o italiano. Além disso, ele foi lido por um coreógrafo francês, George Appaix, da Companhia de Dança La Liseuse, que fez uma coreografia a partir dele e deu a ela o nome de Je ne sais quoi (Não sei o quê). Essa coreografia foi apresentada no teatro da Bastilha em Paris.

Em 2002, começou a implementação do que é hoje o Programa de PósGraduação em Ciências da Linguagem, da Univás, Universidade do Vale do Sapucaí de Pouso Alegre-MG. São 15 anos de estrada, formando pessoas das mais diversas áreas, que depois do mestrado, se voltam para seus objetos de pesquisa entendendo o lugar da linguagem. Tornando possível, além disso, a transformação da universidade e dando condições a mim a outros professores de fazer pesquisa.

Eni Orlandi declara que o que sempre a atraiu, a seduziu na Análise de Discurso é que a AD “ensina a pensar, é que ela nos tira as certezas e o mundo fica mais 
amplo, menos sabido, mais desafiador"3. Minha impressão/leitura é a de que o seu encontro com a Análise de Discurso foi um encontro construído pelo desejo de compreender cada vez mais a linguagem, para cada vez mais compreender o homem, a sociedade, o mundo. Isso porque a Eni Orlandi, naquela mesma entrevista da Fragmentum, e em outros escritos, exposições e falas, mostra que a linguagem se apresentava desde muito cedo na sua vida como um ponto de questão, como algo que a inscreve num laço indelével com as letras, com as palavras, com o silêncio, com a escrita, com a vontade de saber.

Ousar "em não ficar no já sabido" é de certo modo um princípio que a leva a fazer várias travessias e, em uma delas, encontrar a Análise Automática do Discurso; depois, não nessa ordem, Les Vérites de La Palice, e tantos outros textos de Pêcheux e de seu grupo como Paul Henry e Denise Maldidier.

Contudo, Eni Orlandi, movida por esse princípio, com sua força teórica, fez avançar os pressupostos teórico-metodológicos da Análise de Discurso, tornando consequente, consistente um projeto intelectual comprometido com a compreensão da língua na relação com a história, com o sujeito e com a ideologia; com a compreensão do confronto do político com o simbólico. Na travessia, ela apropriou-se, no sentido pêcheutiano do termo, da teoria. Não ficou no mesmo lugar.

Ousou pensar por si mesma, para fazer referência ao fato de "que ninguém pode pensar do lugar de quem quer que seja", como ressalta Pêcheux (1988 [1975], p. 304).

Invenção. Ousou inventar.

De sua força teórica e de sua potência analítica, resultaram deslocamentos teóricos e inúmeras noções com os quais muitos outros pesquisadores vieram a trabalhar e ainda virão a operar. Destaco os estudos sobre:

- a incompletude do sujeito e do sentido, questão introduzida ainda em 1983, em um dos primeiros escritos que foi publicado no Folhetim da Folha de São Paulo;

- paráfrase e polissemia, tensão na qual se dá a produção da linguagem;

- recorte na diferenciação com a segmentação;

- indistinção produzida pela "presença de dois no espaço de um: seja do sentido, seja do sujeito, seja da língua" (ORLANDI, 1996);

- identidade como movimento na história;

- forma-material como forma linguística encarnada na história, acontecimento do significante no sujeito, no mundo;

- a diferença entre ordem e organização estabelecida entre o imaginário e o real;

- a noção e teorização discursiva do silêncio;

- a denominação que "acarreta um silêncio que o fato mesmo de nomear produz" (ORLANDI, 1989, p. 42);

- a distinção entre inteligibilidade, interpretação e compreensão que está no livro Discurso e Leitura, de 1988.

- a definição discursiva de interpretação como mecanismo ideológico;

- a diferença entre interdiscurso (saber discursivo, a memória estruturada pelo esquecimento) e arquivo (memória institucional que se faz lembrar em detrimento daquilo que se faz esquecer);

- memória metálica, aquela que do excesso do dizer, da quantidade e da repetição, a que não falha e que se apresenta como ilimitada;

\footnotetext{
${ }^{3}$ Em entrevista realizada pela Profa. Dra. Raquel Goulart Barreto (UERJ), publicada em: TEIAS, Rio de Janeiro, ano 07, no. 13-14, jan/dez 2006. pp. $01 / 07$. Disponível el https://espacolinguisticouems.wordpress.com/2009/08/25/entrevista-2-profa-dra-eni-p-orlandi/
} 
- a redefinição de texto na Análise de discurso como "unidade de sentido em relação à situação" (ORLANDI, 2001a, p. 42);

- o discurso fundador (ORLANDI, 1993);

- palavra-discurso;

- dígito falho (ORLANDI, 2012);

- a elaboração do processo de individuação do sujeito;

- a concepção de cidade como "acontecimento social por excelência" (ORLANDI, 2004, p. 8);

- o corpo como materialidade específica do sujeito;

- função-autor e efeito-leitor;

- a noção de narratividade, com qual vem trabalhando intensamente nos últimos anos, definindo-a como o modo como a memória se diz;

- sobre o entremeio, que faz com que a prática de interrogar dos limites teóricos, pensar o revés e a reinscrição dos conceitos permaneçam;

- e o político, simbolizando as relações de poder, que incide na divisão dos sujeitos e dos sentidos (ORLANDI, 1998).

Em seu percurso teórico, Eni Orlandi assim faz valer "o principal para quem trabalha com linguagem: não atravessa-la sem se dar conta da sua presença material, da sua espessura, da sua opacidade, da sua resistência" (ORLANDI, 1990, p. 281). Investe na assertiva de que "A vida é função da significação e de gestos de interpretação cotidianos, ainda que não sentidos como tal" (ORLANDI, 1996, p. 10).

Em seu primeiro livro publicado em 1983, A linguagem e seu funcionamento: as formas do discurso, apresenta uma compreensão sobre três tipos de discurso: o lúdico, o polêmico e o autoritário. Sendo que nele, a autora caracteriza o discurso pedagógico como autoritário. Discute as relações entre ensinar, cientificidade, conhecimento, escola e professor, propondo pensar para quem é o discurso pedagógico. Expõe a articulação entre o que ela chama de dois grandes processos que estão na base da produção da linguagem: o parafrástico e polissêmico. Trabalha com a circularidade do discurso pedagógico, com a questão da reversibilidade. Sobre a educação indígena, reflete ao criticar que a "não explicitação da concepção de linguagem do educador (ocidental) coloca esta concepção como geral, como única (a pressuposta), e por isso torna desnecessário o conhecimento da do índio" (ORLANDI, 1983, p.81). Traça o ponto de vista da sociolinguística, da sociologia, da teoria da enunciação até chegar à análise de discurso. Dá ênfase ao funcionamento discursivo, fala da literalidade como produto da história. Em termos operatórios, introduz a diferença entre segmentar e recortar, definindo o recorte como unidade discursiva, fragmento correlacionado de linguagem e situação (p. 139). Pontua que a leitura é produzida. Analisa o silenciamento produzido pelo Discurso da Nova República do que veio antes dela. Opera com as noções de formações imaginárias, formações discursivas, condições de produção. E afirma que aceita "passar pelos mesmos lugares, procurando o que a leva a conhecer alguma coisa a mais a respeito dos objetos provisoriamente tomados para a reflexão, como o discurso pedagógico, o discurso da história, a questão da educação indígena, a argumentação, o discurso religioso e outros" (ORLANDI, 1983, p.9).

Sobre os textos que compõem A linguagem e seu funcionamento: as formas do discurso, Eni Orlandi explica que escreveu:

a maior parte dos artigos no fim dos anos 70 e início dos 80. Época da ditadura, época de forte autoritarismo [...] queria que as pessoas percebessem que não estávamos imunes ao autoritarismo, ou seja, pelo modo como 
funciona a sociedade e a ideologia, nós fazíamos parte desta sociedade autoritária. Queria levar os professores a pensarem suas práticas ${ }^{4}$.

Ela conta também que quando escreveu esse livro, simplesmente o colocou dentro de um envelope e o enviou para a editora Brasiliense, perguntando se tinham interesse e publicá-lo. Ele foi reeditado muitas vezes.

Terra à vista: discurso do confronto: velho e novo mundo é publicado em 1990, pela Editora da Unicamp. Mas sua escrita começa antes, por volta de 1982.

No texto intitulado Pré-liminar que abre esse seu livro, Orlandi reflete sobre o percurso da pesquisa, explica como se deu a construção de seu trabalho cujo percurso começava com o propósito de falar sobre a retórica de contato entre índios e ocidentais, passava pelo discurso da colonização e se desdobrava em direção às várias faces da colonização. Nas palavras da autora: "Entre história, antropologia, literatura e linguística, o tema começou a se mostrar como um percurso em linha reta: as formas colonizadoras do discurso do conhecimento" (ORLANDI, 1990, p. 11-12).

A autora discute sobre o discurso das descobertas, discurso das conquistas ou discurso da dominação. Jogo equívoco, deriva, política do silêncio que perpassa o discurso sobre o índio, o discurso sobre o Brasil. Ela trata do apagamento da história pela noção de cultura; observa que a produção material do que, apagado, toma o nome de ideologia; mostra o confronto entre o discurso da descoberta (de lá para cá) e de origem (daqui para cá); e analisa os sentidos de viagem: "viagem como descoberta, como posse, como administração, missão, diário íntimo, a viagem como possível" (ORLANDI, 1990, p.12).

Orlandi elabora a ideia da colonização como um acontecimento linguístico e explora as formas de discurso investidas na colonização. Pela análise de relatos de missionários e de viajantes, observa os discursos sobre o Brasil e sobre os brasileiros, e analisa os modos de inscrição das línguas nesses relatos. Terra à vista foi traduzido para o francês e, também, publicado na França.

No Prefácio de Análise de Discurso: princípios e procedimentos, livro de 1999, a autora assinala que, longe de supor uma unidade, ou uma homogeneidade para um texto que se espera introdutório, a contribuição está em:

\begin{abstract}
Problematizar as maneiras de ler, levar o sujeito falante ou o leitor a se colocarem questões sobre o que produzem e o que ouvem nas diferentes manifestações da linguagem. Perceber que não podemos não estar sujeitos à linguagem, a seus equívocos, sua opacidade. Saber que não há neutralidade nem mesmo no uso mais aparentemente cotidiano dos signos. A entrada no simbólico é irremediável e permanente: estamos comprometidos com os sentidos e o político. Não temos como não interpretar (ORLANDI, 1999, p.9).
\end{abstract}

Esse livro foi traduzido para o espanhol e publicado no Chile.

Discurso e texto: formulação e circulação dos sentidos é publicado em 2001, e tem início com a apresentação de três momentos do processo de produção do discurso, a saber, a constituição, "a partir da memória do dizer, fazendo intervir o contexto histórico-ideológico mais amplo" (ORLANDI, 2001a, p. 9); a formulação e a circulação. No Prefácio, a autora anuncia que o livro trata mais diretamente da formulação dos discursos e de sua circulação. E o que mais me impressiona é o modo como situa a formulação:

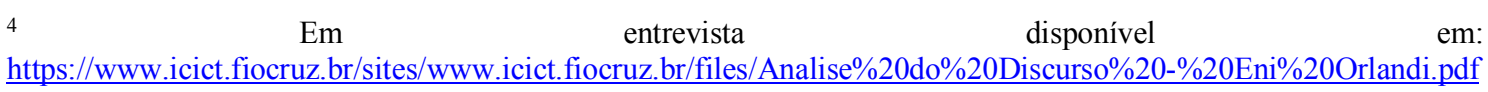


É na formulação que a linguagem ganha vida, que a memória se atualiza, que os sentidos se decidem, que o sujeito se mostra (e se esconde) [...] Formular é dar corpo aos sentidos. E, por ser um ser simbólico, o homem constituindo-se em sujeito pela e na linguagem, que se inscreve na história para significar, tem seu corpo atado ao corpo dos sentidos. Sujeito e sentido constituindo-se ao mesmo tempo têm sua corporalidade articulada no encontro da materialidade da língua com a materialidade da história. Assim entendemos a afirmação de que há um confronto do simbólico com o político (ORLANDI, 2001a, p.9).

A autora trabalha a partir daí com a noção de versão, efeito-leitor, funçãoautor. Analisa o funcionamento do boato. Sobre o sujeito na história e no simbólico, introduz o processo de individuação do sujeito pelo Estado e suas instituições. Tira a pontuação da transparência. Mostra como a TV anula a memória. Reflete sobre os trajetos do dizer entre a ciência e divulgação científica.

Ainda nesse mesmo livro, Orlandi discorre sobre a escrita da Análise de Discurso, dando relevo ao encontro do dispositivo teórico com o dispositivo analítico, acentuando que:

\begin{abstract}
A escrita é tão importante quanto a teoria porque ela vai formular a relação significativa elaborada entre os dois dispositivos que resultará, em um primeiro tempo, na compreensão do objeto simbólico, o discurso, submetido à análise, e em um segundo tempo, em tornar visível para o leitor o movimento da compreensão do analista e, em decorrência, a sua própria posição na interpretação (ORLANDI, 2001a, p. 49).
\end{abstract}

Em Cidade dos Sentidos, publicado em 2004, Orlandi situa o modo como propõe pensar a articulação entre linguagem e espaço urbano. Assinala que, da perspectiva discursiva, a cidade é observada por meio da linguagem. Sendo a linguagem concebida como um observatório dos fenômenos urbanos (ORLANDI, 2004).

Dessa perspectiva, a autora define espaço urbano como um "espaço material concreto funcionando como sítio de significação [...] Um espaço simbólico trabalhado na/pela história, um espaço de sujeitos e de significantes" (ORLANDI, 2001a, p. 186). Especifica que a análise do discurso do urbano se configura "na convergência de dois processos de significação: o da espacialização da linguagem na cidade e o da simbolização do espaço urbano" (ORLANDI, 2001b, p. 7).

Orlandi teoriza sobre o resto, o a-mais, sobre as falas desorganizadas. Explica que a quantidade é estruturante de nossa formação social. Trabalha com o pichador, o que se tatua, o delinquente. Analisa que a construção de um muro, que a implementação de bolsões de condomínios significam uma violência simbólica à medida que se separa "sujeitos de sujeitos igualmente cidadãos" (ORLANDI, 2004, p.84). Mais especificamente sobre o pichador, ela explica que:

Ele se significa na criação de sua letra. Não reconhece/não se reconhece no regime de alfabetização, das letras distribuídas pela escola, na ortografia do certo e do errado [...] Ele resiste com sua letra indecifrável, fazendo deslizar a escritura, produzindo um efeito metafórico da letra, produzindo um sistema de escrita urbano (ORLANDI, 2004, p. 107).

Todo o trabalho de análise e reflexão da autora enfatiza o fato de que as relações sociais são consideradas, na perspectiva da linguagem, como relações de sentidos. Nas palavras de Orlandi: "As relações entre os homens são relações de sentidos e procuramos compreender como isso funciona produzindo efeitos de tal modo que, ao significar, os sujeitos se significam" (ORLANDI, 2004, p. 149). 
Em Língua brasileira e outras histórias: discurso sobre a língua e ensino no Brasil de 2009, Eni Orlandi pesquisa aspectos relevantes da história do estruturalismo no Brasil. Estuda o discurso dos gramáticos em sua produção de gramáticas ou de ensaios, assim como a produção de linguistas. Critica o fato de que a situação da língua portuguesa hoje não cabe mais na estreita noção de lusofonia; propõe desmundializar a reflexão como forma de se confrontar com o discurso da mundialização. Orlandi nos convoca a

com a descolonização, realçar nossa unidade em nossas diferenças: históricas, linguísticas, culturais, sociais, nacionais e de relações internacionais. O que é preciso, diz ela, é tornar visíveis estas diferenças. Falamos diferente. As relações entre nossas línguas formam um intricado quadro de distinções e transformações. E esta a nossa realidade linguística atual (ORLANDI, 2009a, p. 179).

Nesse mesmo livro, relata que realizou pesquisas com grupos indígenas, com os Xerente, na região de Tocantínea, com os Assurini do Xingu. Afirma que:

Não levei questionários preparados, não me posicionei diante dos índios como pesquisador que está lá para tirar-lhes informações. Não segui os métodos dominantes. Fui lá para conhecê-los. Como brasileira que quer conhecer brasileiros que não conhece. Não assumi posição formal como "linguista". Ia tomar banho com eles, ia fazer passeios na "praia", dormia em rede ao lado de outras redes. Observava tudo, sim, mas sem método, sem caderno, sem lápis, sem ideias pré-concebidas. $\mathrm{E}$ ouvi coisas interessantíssimas (ORLANDI, 2009a, p. 14).

Da pesquisa resultou a distinção entre língua imaginária e língua fluida. Orlandi esclarece que:

a língua imaginária é a língua sistema, a que os analistas fixam em suas regras e fórmulas, em suas sistematizações, são artefatos (simulacros) que os analistas de linguagem têm produzido ao longo de sua história e que impregnam o imaginário dos sujeitos na sua relação com a língua [...] A língua fluida é a língua movimento, mudança contínua, a que não pode ser contida em arcabouços e fórmulas, não se deixa imobilizar, a que vai além das normas. A que podemos observar quando focalizamos os processos discursivos, através da história de constituição das formas e sentidos, nas condições de sua produção, na sociedade e na história, afetada pela ideologia e pelo inconsciente. A que não tem limites (ORLANDI, 2009a, p. 18).

É fundamental destacar o título desse livro: Língua Brasileira. Por quê? Porque ele dá nome a nossa língua. Como Eni Orlandi assevera:

Porque pensar o nome da língua é tomar em conta a história do saber produzido sobre ela, é conhecer a história da própria língua em sua prática e funcionamento, é analisar as injunções da conjuntura política e social, é apreender a constituição de seu sujeito, dando mais um passo no saber da história das ideias no Brasil. E é desse modo que tanto especialistas da linguagem assim como os que a praticam e os que praticam seu ensino podem tomar uma posição frente a história da ciência no conjunto de relações que atualmente se articulam no chamado mundo "globalizado", em que o lugar que as línguas ocupam é decisivo (ORLANDI, 2009a, p. 193).

Em 1995, publica na Revista Rua, o artigo Efeitos do verbal sobre o nãoverbal. Nele formula que: 
A significação é um movimento, um trabalho na história e as diferentes linguagens com suas diferentes matérias significantes são partes constitutivas dessa história [...] É no conjunto heteróclito das diferentes linguagens que o homem significa. As várias linguagens são assim uma necessidade histórica (ORLANDI, 1995, p.40).

A existência ou a necessidade histórica de diferentes linguagens reafirmam a incompletude da linguagem e a abertura do simbólico. A autora, com isso, explicita que o sentido não significa de qualquer maneira, ele tem uma matéria própria, precisa de uma "matéria específica para significar [...] Entre as determinações - as condições de produção de qualquer discurso - está a da própria matéria simbólica: o signo verbal, o traço, a sonoridade, a imagem etc. e sua consistência significativa" (ORLANDI, 1995, p. 39). Essa compreensão permite que a análise discursiva da imagem, do som, do corpo, seja praticada.

Orlandi, também, trabalha com diferentes formas de linguagem. Define, por exemplo, a dança como música do corpo, "ritmo significado que liga (estrutura) corpo, espaço e movimento. Uma forma particular de produzir sentido e de se significar" (ORLANDI, 2002). Toma a coreografia como inscrição do corpo no espaço.

Concebe o silêncio como matéria significante. Em As formas do silêncio, busca compreender a relação estabelecida entre linguagem e sua exterioridade face ao processo de significação que implica considerar que todo dizer está ligado com o nãodizer, ou seja, que o discurso é atravessado pelo silêncio. Eni Orlandi enuncia: "quando dizemos que há silêncio nas palavras, estamos dizendo que: elas são atravessadas de silêncio; elas produzem silêncio; o silêncio fala por elas; elas silenciam" (ORLANDI, 1992, p. 14).

Nesse livro dá dimensão política não só à linguagem, mas ao silêncio, assim como o faz no texto Maio de 68: os silêncios da memória.

Em Ciências da Linguagem e Política, de 2014, refletindo sobre a prática científica, a autora retoma e alarga a discussão sobre o fato de que "A teoria é política" (ORLANDI, 2014, p. 36).

No texto Tecnologias da Linguagem: um novo funcionamento, incorporado ao livro O que é Linguística, na edição de 2009, Orlandi reflete sobre o discurso eletrônico enunciando que "A linguagem digital, ou o discurso eletrônico re-organiza a vida intelectual, re-distribui os lugares de interpretação, desloca o funcionamento da autoria e a própria concepção de texto" (ORLANDI, 2009b, p.62-63). Re-situa a escrita como relação social.

O último livro de Eni Orlandi, Eu, Tu, Ele - Discurso e Real da História, acaba de ser publicado. Ele não tem prefácio como todos os outros. Mas, tem posfácio. E nesse posfácio, no último parágrafo do livro, a autora termina formulando que:

mesmo na ilusão de nossas certezas, vivemos o indistinto da linguagem, a incerteza dos sentidos e dos sujeitos, deparando-nos com o que ainda não tem nome, nem face; com o inacabado, o incompleto, o não exato, o múltiplo, o multiforme, o que é sujeito às mudanças [...] E nossa verdade é nosso empenho na conquista de sentidos, de palavras e formas de dizer o que era, ou nos parecia, indizível. Inventar. Conquistar espaços de significação, de interpretação. Formular, ou não, o que ainda não teve formulação. Compreender, ou não, o que era incompreensível: na constituição do sujeito, na relação com a alteridade, e as relações de proximidade, de distância, de separação, de mistura, de incompletude, de equívoco, entre eu, tu e ele (ORLANDI, 2017, p. 335). 
Além das formulações da autora que compõem esse texto-homenagem, cada um certamente guarda uma formulação de Eni Orlandi; guarda uma palavra dela que o toca, que o mobiliza na pesquisa, na reflexão. E talvez o percurso que eu tenha traçado não seja novidade para ninguém. Talvez não tenha conseguido dar a real dimensão do real trabalho realizado pela Eni Orlandi. Afinal, se não há uma correspondência direta entre palavra e coisa, não há também palavra que nela caiba toda uma história. Entretanto, as palavras falam com palavras, como a autora mesma acentua, dando ênfase ao processo, sempre em movimento, da significação.

Percorrer os escritos de Eni Orlandi, investida em homenageá-la, me fez me deparar com a autora, com a pesquisadora de uma maneira singular; fez-me chegar a uma compreensão sobre o lugar da escrita na relação com o sujeito. Mais do que uma forma, como dizia Clarice Lispector: "Escrever é procurar entender, é procurar reproduzir o irreproduzível". Nisto consiste a relação com insabido, com o a-saber. O trabalho de Eni Orlandi, enquanto autora, ou melhor, enquanto aquela que escreve e, com isso, compreende, formula, inventa, dá a ver a escrita/o escrito como um horizonte de significação.

\section{REFERÊNCIAS}

ORLANDI, E. P. A linguagem e seu funcionamento: as formas do discurso. Campinas: Pontes, 1983.

. Discurso e leitura. São Paulo: Cortez, 1988.

"Silêncio e implícito (Produzindo a monofonia)". In: GUIMARÃES, E. (Org.).

História e sentido na linguagem. Campinas: Pontes, 1989, pp. 39-46.

. "Discurso e argumentação: Um observatório do político". Fórum Linguístico, n. 1. Florianópolis, jul-dez., 1998, pp. 73-81.

. Terra à vista - Discurso do confronto: Velho e novo mundo. Campinas: Editora da Unicamp, 1990.

As formas do silêncio: No movimento dos sentidos. Campinas: Editora da Unicamp, 1992.

- (Org.). Discurso fundador: A formação do país e a construção da identidade nacional. Campinas: Pontes, 1993.

"Discurso, imaginário social e conhecimento". Em Aberto, ano 14, n. 61. Brasília, jan.-mar., 1994, pp. 53-59. 1995, pp. 35-48.

"Efeitos do verbal sobre o não verbal". Rua, n. 1. Campinas, Unicamp, mar.,

Interpretação: Autoria, leitura e efeitos do trabalho simbólico. Rio de Janeiro: Vozes, 1996.

Análise de discurso: Princípios e procedimentos. Campinas: Pontes, 1999.

"Maio de 1968: Os silêncios da memória". In: ACHARD, Pierre et al. (Orgs.), Papel da memória. Campinas: Pontes, 1999, pp. 59-67.

Discurso e texto: Formulação e circulação dos sentidos. Campinas: Pontes, 2001a. 
. "Tralhas e troços: O flagrante urbano". In: ORLANDI, E. (Org). Cidade atravessada: Os sentidos públicos no espaço urbano. Campinas: Pontes, 2001b, pp. 924.

Dança e Discurso. In: SIMPÓSIO INTERNACIONAL DANÇA EM CADEIRA DE RODAS, I., 2001, Campinas. Anais..., Curitiba: ABRADECAR, 2001.

- Coreografar: inscrever significativamente o corpo no espaço. In: FERREIRA, E.; FERREIRA, M. B. R.; FORTI, V. A. M. (Orgs). Interfaces da dança para pessoas com deficiência. Campinas: CBDCR, 2002.

. Cidade dos sentidos. Campinas: Pontes, 2004.

. Língua brasileira e outras histórias: discurso sobre a língua e ensino no Brasil. Campinas: Pontes, 2009a.

. Tecnologias da linguagem: um novo funcionamento. O que é linguística. $2^{\mathrm{a} e d . ~ S a ̃ o ~ P a u l o: ~ B r a s i l i e n s e, ~ 2009 b . ~}$

Discurso em análise: Sujeito, sentido, ideologia. Campinas: Pontes, 2012.

. Ciências da Linguagem e Política: anotações ao pé das letras.

Campinas: Pontes, 2014.

Eu, Tu, Ele: Discurso e real da História. Campinas: Pontes, 2017.

PÊCHEUX, M. Semântica e discurso: Uma crítica à afirmação do óbvio. Trad. E. P. Orlandi et al. Campinas: Editora da Unicamp, 1988 [1975].

SCHERER, A. História das idéias x história de vida. Fragmentum, no. 7, mar. 2004.

Recebido em: agosto de 2017.

Aprovado em: setembro de 2017.

Como citar este trabalho:

COSTA, G. C. da. Habitar o insabido: encontro, travessia, invenção. Traços de linguagem, v. 2, n. 1, p. 50-61, 2018. 